Cite this: RSC Adv., 2017, 7, 7920

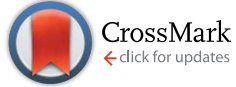

Received 19th December 2016 Accepted 13th January 2017

DOI: 10.1039/c6ra28387j

www.rsc.org/advances

\section{Structural, electronic and catalytic performances of single-atom Fe stabilized by divacancy-nitrogen- doped graphene $\uparrow$}

\begin{abstract}
Zhiyong Liu, ${ }^{a}$ Tingwei He, ${ }^{a}$ Kaikai Liu, ${ }^{a}$ Weiguang Chen ${ }^{\mathrm{b}}$ and Yanan Tang*ab
Inspired by the experimental discovery of the configuration of a one central transition metal and four surrounding $\mathrm{N}$ atom doped graphene sheet (M-GN4), we systemically study the geometry and electronic and catalytic properties of a single-atom Fe embedded GN4 sheet (Fe-GN4) using firstprinciples calculations. It is found that the neighboring $\mathrm{N}$ atoms in graphene strongly stabilize a single $\mathrm{Fe}$ atom and make the doped Fe atom more positively charged, which helps to regulate the stability of reactive gases. Besides, the adsorption of gas molecules can modulate the electronic structure and magnetic property of the Fe-GN4 system. Moreover, the catalytic reactions of $\mathrm{CO}$ oxidation on the FeGN4 substrate are comparably investigated in terms of the Langmuir-Hinshelwood (LH) and Eley-Rideal (ER) mechanism. The results show that the $\mathrm{LH}$ reaction as the starting state is energetically more favorable than the ER reaction, since the catalytic process has much smaller energy barriers $(0.13 \mathrm{eV})$ and then promotes the $\mathrm{CO}$ oxidation reaction. Therefore, the stable configuration of Fe-GN4 would be a highly efficient catalyst for $\mathrm{CO}$ oxidation, which provides a clue for designing atomic-scale catalysts in energy-related devices.
\end{abstract}

\section{Introduction}

The catalytic oxidation of carbon monoxide (CO) as a vital prototype reaction plays a very important role in solving the serious environmental problems caused by automobile exhaust and industrial processes, ${ }^{1-3}$ and can be used to evaluate the reactive activity, selectivity and durability of catalysts in surface chemistry. ${ }^{4-6}$ Following the previous works on many noble metals surfaces are studied for catalyzing CO oxidation, ${ }^{7-9}$ such as $\mathrm{Pt},{ }^{2,10,11} \mathrm{Rh},{ }^{12} \mathrm{Au}^{\mathbf{4}, 13-15}$ and $\mathrm{Pd} .{ }^{3}$ Recently, novel low dimensional nanoparticles ${ }^{\mathbf{1 6 - 1 9}}$ and even single atoms ${ }^{20}$ have been suggested for improving the catalytic reactivity of CO oxidation. Single-atom catalyst loading on various metal oxide substrates $\left(\mathrm{FeO}_{x},{ }^{21,22} \mathrm{ZnO},{ }^{23} \mathrm{CeO}_{2},{ }^{24,25} \mathrm{MnO}_{2}\right.$ (ref. 26) and $\mathrm{MoS}_{2}$ (ref. 27)) demonstrates the excellent catalytic property toward CO oxidation. These results illustrated that the $\mathrm{CO}$ oxidation reaction takes place mainly on the surface of doped metal oxide, and the adsorption of $\mathrm{CO}$ can react with surface oxygen to form $\mathrm{CO}_{2}$. In addition, the large surface-to-volume ratio of graphene as a promising substrate exhibits outstanding physical and chemical properties. ${ }^{28-31}$ The experimental results confirmed

${ }^{a}$ College of Physics and Materials Science, Henan Normal University, Xinxiang, Henan, 453007, China. E-mail: yntang2010@163.com

${ }^{b}$ Quantum Materials Research Center, College of Physics and Electronic Engineering, Zhengzhou Normal University, Zhengzhou 450044, China

$\dagger$ Electronic supplementary information (ESI) available. See DOI: $10.1039 / \mathrm{c} 6 \mathrm{ra} 28387 \mathrm{j}$ that Pt catalysts were well-dispersed on graphene nanosheets ${ }^{32}$ or graphene oxide, ${ }^{33}$ and can reduce both $\mathrm{CO}$ adsorption and the activation barriers for $\mathrm{CO}$ oxidation, which is of great significance in energy-related applications. ${ }^{34-39}$ However, the metal adatoms easily aggregate into large clusters and then affect the efficiency of the catalyst. ${ }^{40}$ Therefore, it is a major challenge to explore appropriate substrates that can enhance the stability and chemical reactivity of catalysts.

To solve this problem, chemical doping has been confirmed to be an effective approach to tailor the properties of graphene $;^{\mathbf{4 1 - 4 8}}$ especially, the substitutional dopants in graphene can control the size and degree of catalyst dispersion ${ }^{49-53}$ and result in excellent catalytic activity. ${ }^{54-57}$ Although the singleatom $\mathrm{Au}_{-},{ }^{58} \mathrm{Fe}-{ }^{59,60} \mathrm{Cu}_{-},{ }^{61} \mathrm{Pt}-{ }^{62}{ }^{2} \mathrm{Pd}^{-63}$ and $\mathrm{Al}^{64}$ embedded graphene substrates have high catalytic activity for $\mathrm{CO}$ oxidation, it is still highly desirable to develop the realization of a singleatom catalyst which relies on the controllable generation of vacancies in graphene sheets. Recently, works have proposed that active sites would consist of a metal atom coordinated by four pyridinic $\mathrm{N}$ atoms and are incorporated into graphitic sheets (M-GN4), ${ }^{65-67}$ which can modify the electronic and magnetic properties of graphene ${ }^{68}$ and show good activity for the oxygen reduction reaction (ORR). ${ }^{69,70}$

The computational studies revealed that the ORR activity of Fe-GN4 moieties is comparable with that of Pt-based catalysts, ${ }^{71,72}$ which stimulates the ongoing debate on whether the Fe-GN4 sheets can be efficient catalysts for CO oxidation. This issue is unresolved, largely due to the lack of knowledge on the 
origin of the reaction mechanism toward $\mathrm{CO}$ oxidation on the metal-N4 moiety doped graphene. Recently, Zhang et al. ${ }^{73}$ investigated the catalytic activity for CO oxidation on Co atoms incorporated with pyridinic nitrogen graphene (Co-GN3). Yet, there is a lack of systematic analysis of the sensing performance of the M-GN4 surface toward adsorbed gases and their interaction in catalytic reactions.

The previous works studied the catalytic reaction of $\mathrm{CO}$ oxidation on different non-noble metal (NNM, Ni, Co and Al) atom anchored graphene systems. ${ }^{74,75}$ Herein, we chose $\mathrm{Fe}$ as the catalyst, because it is inexpensive and abundant in the earth. Moreover, the metal Fe coupled with $\mathrm{N}$-doped graphene plays a vital role in enhancing ORR activity by improving the content of the Fe-N active sites. ${ }^{72}$ It is natural to ask whether the Fe-GN4 sheet can be used to achieve new functionalities. In this work, the adsorption stability and interaction of reactive gases ( $\mathrm{CO}$ and $\mathrm{O}_{2}$ ) on the Fe-GN4 surface are investigated. The sequential $\mathrm{CO}$ oxidation reactions on Fe-GN4 are comparably analyzed through considering both the Langmuir-Hinshelwood (LH) and Eley-Rideal (ER) mechanisms.

\section{Computational model and methods}

Spin-polarized density functional theory (DFT) calculations are carried out using the Vienna $a b$ initio simulation package (VASP) ${ }^{76,77}$ with the projector augmented wave (PAW) pseudopotentials. ${ }^{78}$ Exchange-correlation functions are described with the generalized gradient approximation (GGA) in the form of the Perdew, Burke, and Ernzerhof (PBE) functional. ${ }^{79}$ The kinetic energy cutoff for the plane-wave basis set was chosen to be $450 \mathrm{eV}$. The $\mathrm{C} 2 \mathrm{~s}^{2} 2 \mathrm{p}^{2}$, Fe $3 \mathrm{~d}^{6} 4 \mathrm{~s}^{2}, \mathrm{~N} 2 \mathrm{~s}^{2} 2 \mathrm{p}^{3}$ and $\mathrm{O} 2 \mathrm{~s}^{2} 2 \mathrm{p}^{4}$ states are treated as valence electrons. An armchair edge of graphene ribbon with a $5 \times 7$ supercell is adopted and the vacuum layer is set to $20 \AA$ to avoid the interaction among mirror images. The calculated lattice constant of the graphene sheet is $2.47 \AA$, which approximates well to the experimental value of $2.46 \AA^{80}$ The Brillouin zone (BZ) integration is sampled using a $3 \times 3 \times 1$ $\Gamma$-centered Monkhorst-Pack (MP) grid and a $\Gamma$-centered MP grid of $15 \times 15 \times 1$ is used for the final density of states (DOS) calculations.

Bader charge analysis ${ }^{\mathbf{8 1}}$ was used to evaluate the atomic charges and electron transfer in the reactions. The adsorption energies and site preferences for each type of gas molecule are tested on the Fe-graphene surfaces. The climbing image nudged elastic band method (CI-NEB) ${ }^{82-84}$ was employed to investigate the saddle points and minimum energy path (MEP) for the formation (or dissociation) of reaction gases on graphene substrates. The geometric optimization and the search for the transition states (TS) are tested by means of frequency calculations, while those with one imaginary frequency correspond to the metastable states. A number of intermediate images are constructed along the reaction pathways between the initial state (IS) or TS and the final state (FS), and the spring force between adjacent images was set to be $5.0 \mathrm{eV} \AA^{-1}$. The images are optimized until the forces on each atom are less than
$0.02 \mathrm{eV} \AA^{-1}$. The energy barriers $\left(E_{\text {bar }}\right)$ of each chemical reaction are calculated by the energy difference between the IS and TS.

The adsorption energy ( $\left.E_{\text {ads }}\right)$ is calculated using the formula $E_{\text {ads }}=E_{\mathrm{A}}+E_{\mathrm{B}}-E_{\mathrm{AB}}$, where $E_{\mathrm{A}}, E_{\mathrm{B}}$ and $E_{\mathrm{AB}}$ are the total energies of the optimized adsorbates in the molecules or atoms (A: Fe, $\mathrm{O}_{2}$ $\mathrm{O}, \mathrm{CO}$ and $\mathrm{CO}_{2}$ ), the clean graphene substrates (B: GN4 or FeGN4) and the adsorbate-substrate systems, respectively. With this definition, a higher $E_{\text {ads }}$ value means a stronger adsorption.

\section{Results and discussion}

3.1. Geometric stability and electronic properties of the FeGN4 sheet

Based on the previous calculations, ${ }^{85,86}$ the formation configuration of one central transition metal and four surrounding $\mathrm{N}$ atoms is energetically favorable for three reasons: (1) creation of carbon divacancies, (2) $\mathrm{N}$ atom substitution of unsaturated carbons and (3) the metal atom incorporation into the center of the $\mathrm{N}$ atoms, as depicted in Fig. 1(a). It was reported that the FeGN4 structure is energetically more favorable than the formation of Fe-GN3, Fe-GN2, Mn-GN4 and Co-GN4 configurations. ${ }^{65}$ In order to ensure the most stable configuration of the Fe atom on the GN4 surface, we have performed a scan in energy of the adsorbed Fe atom at the possible adsorption sites, which include the centers of the substitution $\mathrm{N}$ atoms and the neighboring hexagonal carbon ring $(\mathrm{H}$, the hollow site), as well

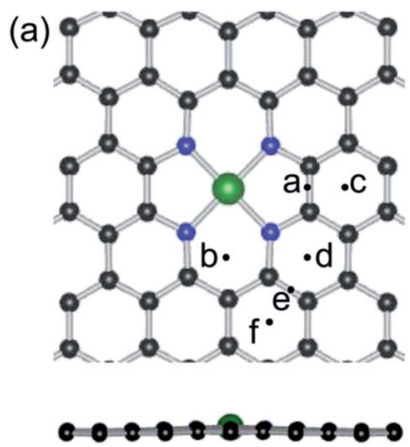

(b)

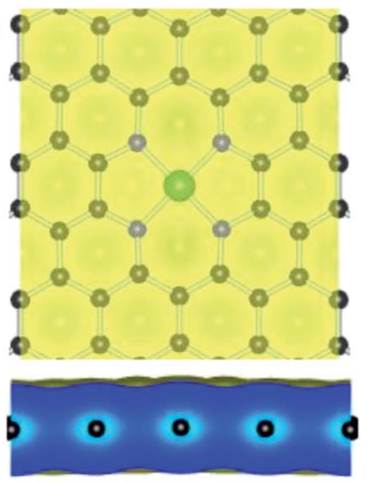

(c)

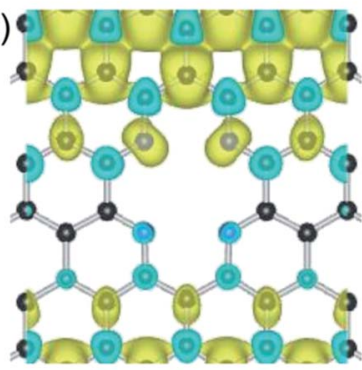

(d)

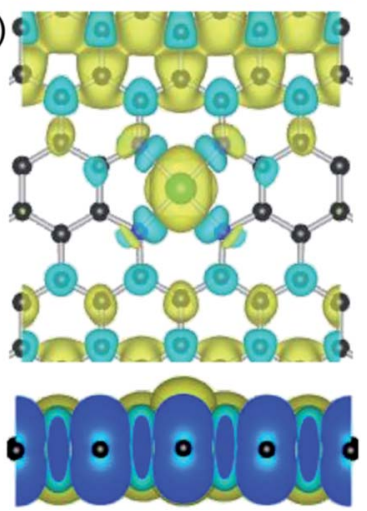

Fig. 1 Top and side views of the (a) geometric structure and (b) charge distribution for the Fe-GN4 sheet, as well as the spin charge density plots for the (c) GN4 and (d) Fe-GN4 systems. Black, blue and green balls represent the $\mathrm{C}, \mathrm{N}$ and Fe atoms, respectively. 
as the bridge (B) sites of the $\mathrm{C}-\mathrm{C}$ bonds in the same carbon rings. The calculated results show that the Fe atom anchors at the $\mathrm{H}$ (or $\mathrm{B}$ ) of the $\mathrm{a}$ and $\mathrm{b}$ sites, where the adatom would be drawn back to the vacancy site of the GN4 sheet, as shown in Fig. 1(a). For the other sites (c, d, e and f) further away from the vacancy site, the Fe adatom would be anchored at the neighboring $\mathrm{H}$ site with $E_{\mathrm{ads}}$ of about $1.53 \mathrm{eV}$. These results indicate that the Fe adatom is more likely to be anchored at the vacancy site of the GN4 surface and forms the more stable configuration of the Fe-GN4 sheet. The calculated adsorption energy, bond length and transferred electrons of the Fe-GN4 structure are shown in Table 1; the $\mathrm{Fe}, \mathrm{N}$ and $\mathrm{C}$ atoms are all in the same plane in the optimized structure.

Based on the Bader charge analysis, ${ }^{81}$ the atomic Fe exhibits positive charge due to the transferring electrons (1.36e) that move from the $\mathrm{Fe}$ atom to the neighboring $\mathrm{N}$ atoms and form the covalent feature between the Fe and $\mathrm{N}$ atoms, while the four $\mathrm{N}$ atoms are negatively charged to about $0.66 e$. Compared with the $\mathrm{Fe}$ adatom on the pristine graphene surface $(1.19 \mathrm{eV})$, the doped Fe atom at the GN4 sheet (Fe-GN4) has a much larger $E_{\text {ads }}(7.77 \mathrm{eV})$, which is larger than that of the cohesive energy of the Fe element of $4.94 \mathrm{eV}$ per atom, and the monovacancy and divacancy sites of the graphene sheet $(7.28$ and $6.47 \mathrm{eV}$, respectively). Thus, the formation of the Fe-GN4 configuration is energetically favorable and stable enough in the chemical reaction. Besides, the bond distance between the Fe atom and the neighboring $\mathrm{N}$ atoms is $1.87 \AA$, which is in agreement with the reported results. ${ }^{65,85}$ As shown in Fig. 1(b), the distributions of charge density occur at interfaces between the Fe atom and neighboring $\mathrm{N}$ atoms, where the corresponding contour lines in

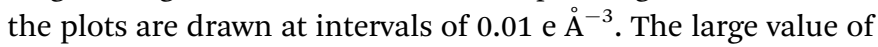
the electron distribution occurs at the $\mathrm{Fe}-\mathrm{N}$ bonds, illustrating that the transferred electrons $(>1.0 e)$ can enhance the stability of the Fe atom. In order to confirm the stable configuration of the Fe-GN4 sheet, first principles molecular dynamics calculations were performed. Herein, a time step of $1.0 \mathrm{fs}$ was used and the temperature was controlled by velocity scaling at each step. In a period of $2000 \mathrm{fs}$ ( $2 \mathrm{ps}$ ), with calculations at temperatures of $700 \mathrm{~K}, 1000 \mathrm{~K}$ and $1300 \mathrm{~K}$, the embedded Fe atom and the neighboring $\mathrm{N}$ atoms in the plane have slight distortion, as shown in Fig. S1.† The configuration of Fe-GN4 is even still stable in a period of $2 \mathrm{ps}$ at $1300 \mathrm{~K}$ with some distortion over time, which is confirmed by the change in height of the $\mathrm{Fe}$ dopant (from 0.07 to $0.21 \AA$ ) and the change in distance of the

Table 1 The adsorption energy ( $E_{\text {ads, }}$ in $\mathrm{eV}$ ), bond length of $\mathrm{Fe}-\mathrm{N}$ or $\mathrm{O}_{2}, \mathrm{CO}, \mathrm{O}$ and $\mathrm{CO}_{2}\left(d_{1}\right.$, in $\left.\AA\right)$, adsorption height $\left(d_{2}\right.$, in $\AA$ ), and the number of electrons transferred from the adsorbate to the substrate $(\Delta q$, the "+"or "-" denotes gaining or losing electrons), for the $\mathrm{Fe}$ dopant or gas molecules adsorbed on the GN4 or Fe-GN4 surface.

\begin{tabular}{llllll}
\hline Systems & & $E_{\text {ads }}(\mathrm{eV})$ & $d_{1}(\AA)$ & $\Delta q(\mathrm{e})$ & $d_{2}(\AA)$ \\
\hline $\mathrm{GN} 4$ & $\mathrm{Fe}$ & 7.77 & 1.87 & -1.36 & 0.06 \\
Fe-GN4 & $\mathrm{O}_{2}$ & 0.95 & 1.39 & +0.81 & 1.85 \\
& $\mathrm{CO}$ & 1.19 & 1.17 & +0.32 & 1.71 \\
& $\mathrm{O}$ & 4.56 & 1.91 & +0.72 & 1.65 \\
& $\mathrm{CO}_{2}$ & 0.12 & 1.16 & +0.18 & 1.65
\end{tabular}

Fe-N bonds (from 1.79 to $1.97 \AA$ ). This result indicates that the GN4 configuration could efficiently stabilize the single-atom catalyst, and the Fe-GN4 sheet as an active site possesses high thermal stability at a certain temperature.

Secondly, we investigate the spin charge density (SCD) for the GN4 and Fe-GN4 systems as depicted in Fig. 1(c) and (d), where the corresponding contour lines in the plots are drawn at intervals of $0.001 \mathrm{e}^{-3}$. It is found that more electrons dominantly accumulate in the vicinity of the $\mathrm{Fe}-\mathrm{N}$ bonds, and fewer electrons are located on neighboring carbon atoms. It is clearly shown that the doped Fe atom induces the greater spin electron redistributions of the GN4 system, resulting in the magnetic moment of the system increasing from $10.0 \mu_{\mathrm{B}}$ (GN4) to $12.0 \mu_{\mathrm{B}}$ (Fe-GN4). In order to analyze the origin of the high stability of the Fe-GN4 sheet, more insight into the corresponding electronic structure of the system is shown in Fig. 2. It is found that the total DOS (TDOS) and partial DOS (PDOS) plots of the FeGN4 system have been obviously altered as compared with those of the bare GN4 sheet. A peak at the Fermi level $\left(E_{\mathrm{F}}\right)$ vanished in the GN4 system, and there is a small band gap at the $E_{\mathrm{F}}$ in the Fe-GN4 system, meaning that the semimetal GN4 system converts into a semiconducting material. Besides, the broadened Fe 3d states strongly overlap with the TDOS of the system around the $E_{\mathrm{F}}$, suggesting that the strong hybridization between the Fe atom and the GN4 system can enhance their interaction. The asymmetry of the spin channels in the GN4 and Fe-GN4 sheets indicates that these systems exhibit magnetic character. Thus, the doped Fe atom can regulate the electronic structure and magnetic properties of the GN4 system.

\subsection{Adsorption properties of $\mathrm{CO}$ and $\mathrm{O}_{2}$ molecules}

Based on the optimized configuration of the Fe-GN4 substrate, we firstly investigate the stable configurations of various

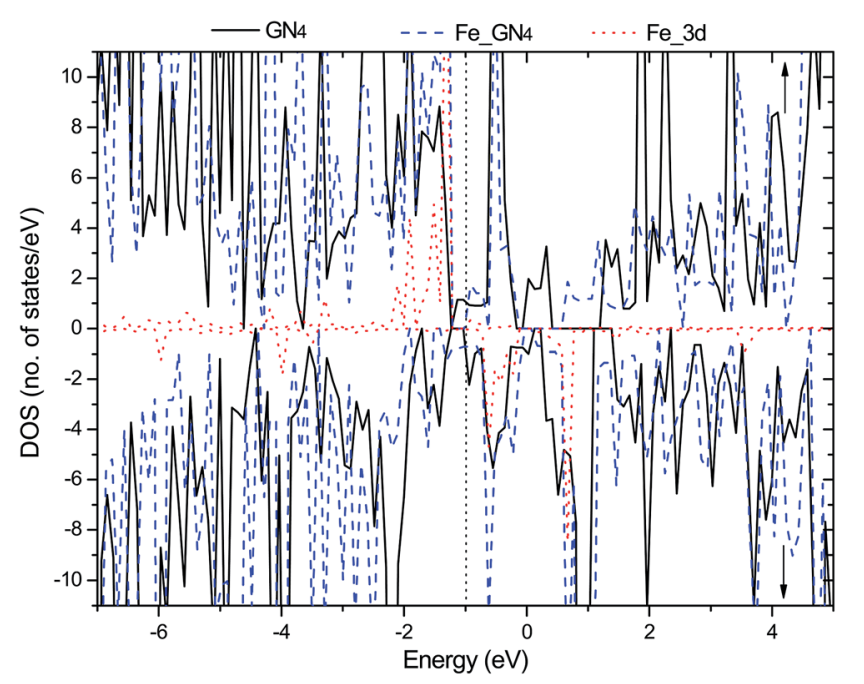

Fig. 2 Spin-resolved total DOS (TDOS) and partial DOS (PDOS) (spinup labeled with $\uparrow$ and spin-down labeled with $\downarrow$ ) for the Fe-GN4 system. The black solid, blue dashed and red dotted curves represent the TDOS of GN4 and Fe-GN4 and the PDOS of the Fe $3 d$ states, respectively. The vertical dotted line denotes the Fermi level. 
adsorbed species $\left(\mathrm{O}_{2}, \mathrm{CO}, \mathrm{O}\right.$ and $\left.\mathrm{CO}_{2}\right)$. For the most stable adsorption configurations, the corresponding adsorption energies and structural parameters are listed in Table 1. It is found that the adsorption of $\mathrm{CO}$ on the $\mathrm{Fe}-\mathrm{GN} 4$ surface is more stable than that of the $\mathrm{O}_{2}$ molecule. As shown in Fig. 3(a), the $\mathrm{O}_{2}$ prefers to form two bonds with the $\mathrm{Fe}$ atom and the $\mathrm{O}-\mathrm{O}$ bond is parallel to the Fe-GN4 surface (1.85 $\AA$ ), and the corresponding $E_{\text {ads }}$ is $0.95 \mathrm{eV}$. As shown in Fig. 3(b), the end-on configuration of $\mathrm{CO}$ is nearly vertical on the $\mathrm{Fe}-\mathrm{GN} 4$ surface with the distance between Fe and CO being $1.71 \AA$; it has a larger $E_{\text {ads }}(1.19 \mathrm{eV})$ than the adsorbed $\mathrm{O}_{2}$. Compared with the $\mathrm{CO}$ adsorption $(0.32 e)$, more electrons $(0.81 e)$ are transferred from the Fe-GN4 to the adsorbed $\mathrm{O}_{2}$, which subsequently leads to elongation of (a)

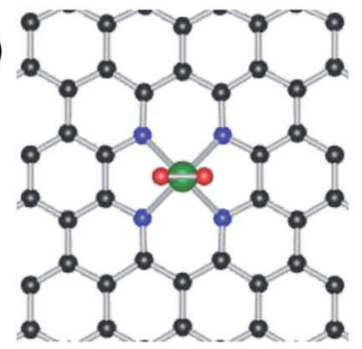

(c)
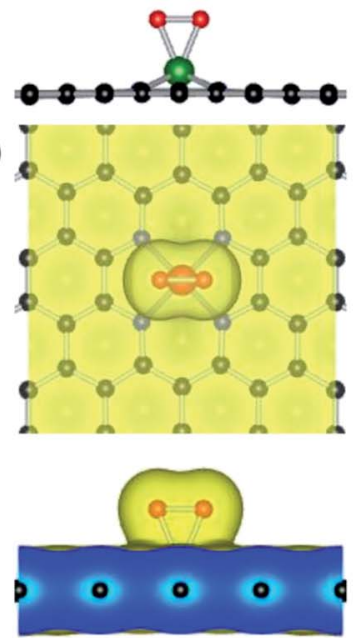

(e)
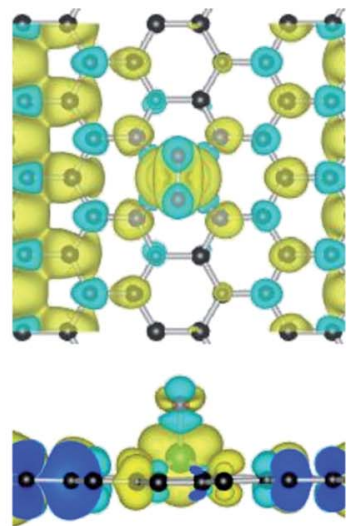

(b)

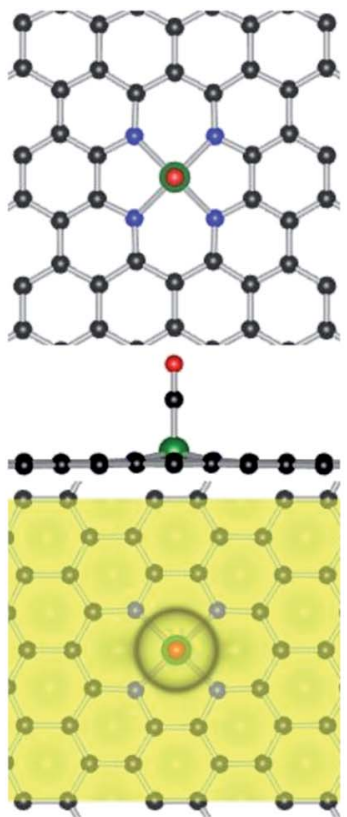

(d)

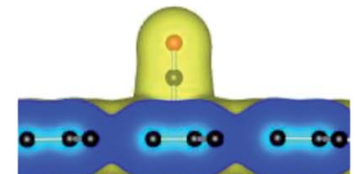

(f)
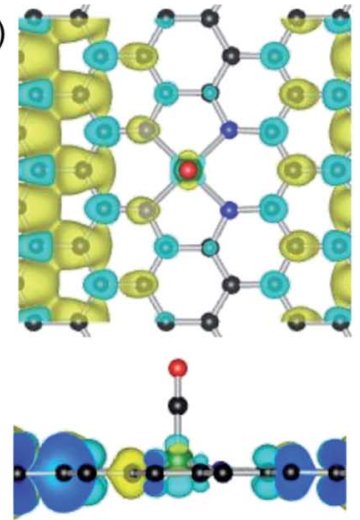

Fig. 3 Top and side views of the ( $a$ and $b$ ) geometric structures, ( $c$ and d) charge distribution and (e and f) spin charge density plots for $\mathrm{O}_{2}$ and $\mathrm{CO}$ adsorbed on the Fe-GN4 surface. Black, blue, red and green balls represent the $\mathrm{C}, \mathrm{N}, \mathrm{O}$ and Fe atoms, respectively. the $\mathrm{O}-\mathrm{O}$ bond $(1.39 \AA)$. Hence, the elongation of the $\mathrm{O}-\mathrm{O}$ bond is connected to the number of transferred electrons from the $\mathrm{Fe}-\mathrm{GN} 4$ substrate. The more charge that is transferred from FeGN4 to $\mathrm{O}_{2}$, the more elongated the $\mathrm{O}-\mathrm{O}$ bonds become. ${ }^{62}$

As shown in Fig. 3(c) and (d), we investigate the valence charge density between reactive gases and the Fe-GN4 sheet. It is found that the more the electrons dominantly accumulate in the vicinity of the $\mathrm{CO}-\mathrm{Fe}$ and $\mathrm{O}_{2}-\mathrm{Fe}$ interfaces, the fewer electrons are located on the graphene substrates. Bader charge analysis shows that the doped $\mathrm{Fe}$ atom provides transferred electrons of about 1.38 and $1.61 e$ in the two systems, which are partly transferred to the adsorbed gases $(0.32 e$ for $\mathrm{CO}$ and $0.81 e$ for $\mathrm{O}_{2}$ ) and the rest are transferred to the GN4 substrates, illustrating that the doped metal atoms can enhance the interaction between reactants and substrates. In addition, we further investigate the spin electron redistribution for gas molecules on the Fe-GN4 substrate, as shown in Fig. 3(e) and (f). It is found that the adsorbed $\mathrm{O}_{2}$ and $\mathrm{CO}$ induce the spin charge redistribution of the GN4 surfaces. The more the electrons dominantly accumulate in the vicinity of the $\mathrm{O}_{2}-\mathrm{Fe}$ interfaces, the much fewer electrons are located at the $\mathrm{CO}-\mathrm{Fe}$ interfaces and the GN4 surface. Compared to the adsorbed $\mathrm{CO}\left(10.0 \mu_{\mathrm{B}}\right)$, the adsorption of $\mathrm{O}_{2}$ on the $\mathrm{Fe}-\mathrm{GN} 4$ system exhibits a more pronounced spin charge distribution and thus has a better magnetic property $\left(12.0 \mu_{\mathrm{B}}\right)$. Hence, the positive charge of the Fe dopant can regulate the adsorption behaviors for gas molecules and the adsorbed gases can control the magnetic property of the $\mathrm{Fe}-$ GN4 system. Although the adsorbed CO has a relatively large $E_{\text {ads }}$ on the Fe-GN4 surface, the small energy difference of the adsorption gases indicates a relatively smaller repulsion between the reactive gases, which may facilitate the interaction between $\mathrm{CO}$ and $\mathrm{O}_{2} \cdot{ }^{57}$

Electronic structure, which fundamentally determines the physical and chemical properties of a system, is directly related to the kind of reactant gases on the substrate. For the adsorbed $\mathrm{O}_{2}$ and $\mathrm{CO}$ on the Fe-GN4 systems, the corresponding DOS plots are investigated, which are shown in Fig. 4. As shown in Fig. 4(a), the broadened PDOS of the Fe 3d states strongly hybridize with the $\mathrm{O}_{2} 2 \pi^{*}, 5 \sigma$ and $1 \pi$ orbitals around the $E_{\mathrm{F}}$. The reduced peaks below the $E_{\mathrm{F}}$ indicate that the transferred electrons $(0.81 e)$ are closer to the $\mathrm{O}_{2}$ and occupy the $2 \pi^{*}$ and $5 \sigma$ states of $\mathrm{O}_{2}$, resulting in the elongation of the $\mathrm{O}-\mathrm{O}$ bond to 1.39 $\AA$. Besides, the increased unpaired electrons between the adsorbed $\mathrm{O}_{2}$ and $\mathrm{Fe}$ atom induce the magnetic moment of the whole system $\left(12.0 \mu_{\mathrm{B}}\right)$, so the spin-up and spin-down channels of the system become asymmetric, which is similar to $\mathrm{Au}^{-58}$ and Cu-graphene. ${ }^{61}$ The DOS plot for the adsorbed $\mathrm{CO}$ on the FeGN4 system is shown in Fig. 4(b); the hybridization between the PDOS of the Fe $3 \mathrm{~d}$ states and CO- $2 \pi^{*}, 5 \sigma$ states is observed near the $E_{\mathrm{F}}$. Compared to the adsorbed $\mathrm{O}_{2}$, fewer electrons are transferred from the $\mathrm{Fe}$ atom to the $\mathrm{CO}$ molecule $(0.32 e)$. According to the asymmetry of the spin channels, the adsorbed $\mathrm{CO}$ on the Fe-GN4 system exhibits the magnetic property (10 $\left.\mu_{\mathrm{B}}\right)$. Therefore, the electronic and magnetic properties of the FeGN4 sheet can be regulated by choosing the kinds of reactive gases, which may have a bearing on important applications in electronic and spintronic devices. 

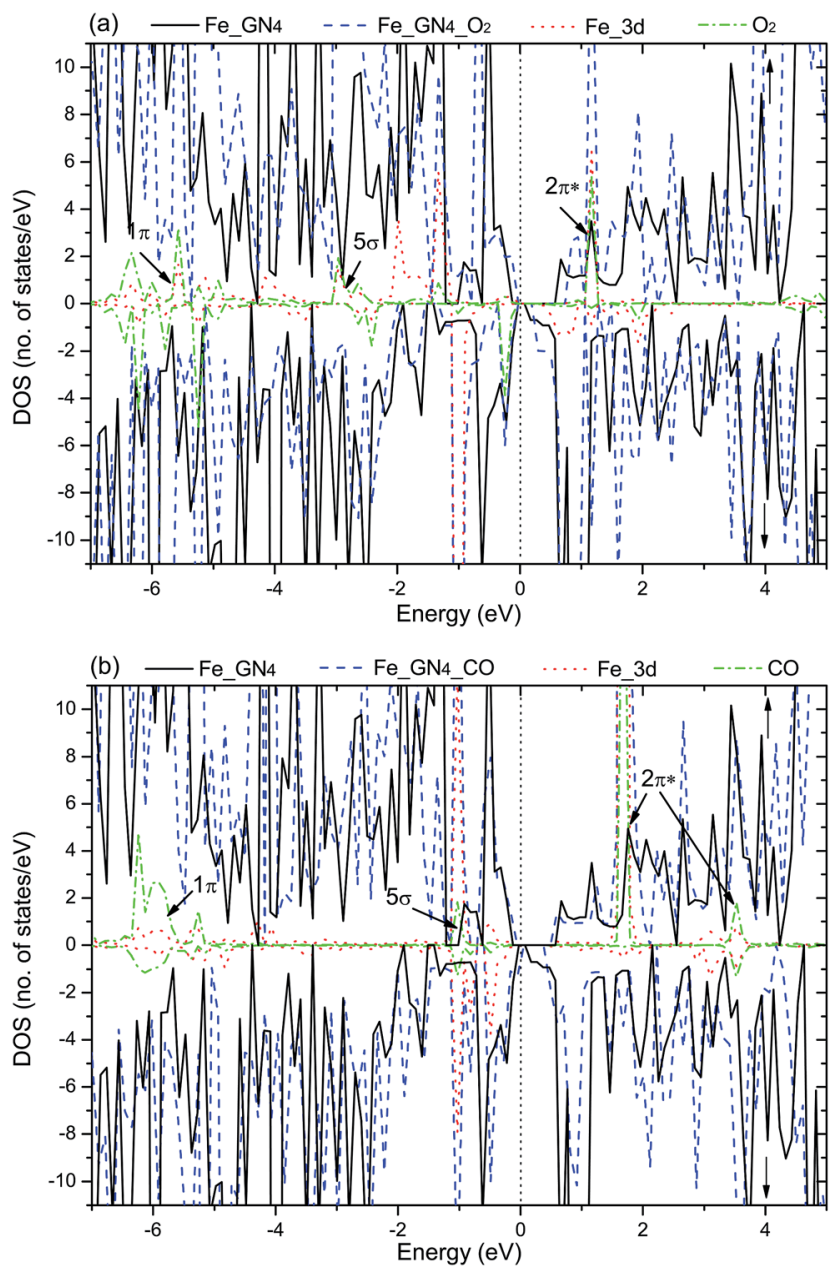

Fig. 4 Spin-resolved TDOS, local DOS (LDOS), PDOS (spin-up labeled with $\uparrow$ and spin-down labeled with $\downarrow$ ) for (a) $\mathrm{O}_{2}$ and (b) $\mathrm{CO}$ adsorbed on the Fe-GN4 sheet. The black solid and blue dashed curves represent the TDOS of the Fe-GN4 system without and with, respectively, $\mathrm{O}_{2}$ or $\mathrm{CO}$ adsorption. The red dotted and green dash dotted curves represent the PDOS of $\mathrm{Fe} 3 \mathrm{~d}$ states with $\mathrm{O}_{2}$ or $\mathrm{CO}$ adsorption and the LDOS of adsorbed $\mathrm{O}_{2}$ (or CO), respectively. The vertical dotted line denotes the Fermi level.

\subsection{Reaction mechanism of CO oxidation}

Two types of reaction mechanism for $\mathrm{CO}$ oxidation have been established, namely, the LH and ER mechanisms. ${ }^{87-89}$ The LH mechanism occurs with the coadsorption of $\mathrm{CO}$ and $\mathrm{O}_{2}$ molecules before reaction, followed by formation and dissociation of a peroxo-type OOCO intermediate state (MS). Finally, the formation and desorption of a $\mathrm{CO}_{2}$ molecule occurs, leaving an adsorbed $\mathrm{O}$ atom $\left(\mathrm{O}_{\mathrm{ads}}\right)$ at the catalyst. The ER mechanism features the $\mathrm{CO}$ molecule directly reacting with the preadsorbed $\mathrm{O}_{2}$ and the subsequent dissociation of the carbonate-like state $\mathrm{CO}_{3}$ (MS). In this study, both reaction mechanisms are comparatively investigated here to identify the optimal reaction pathway.

3.3.1. LH mechanism. For the CO oxidation reactions, the atomic structures of various states along the MEP of the LH mechanism and the corresponding structure parameters for IS,
TS, MS and FS are displayed in Fig. 5 and Table 2, respectively. The coadsorption of the $\mathrm{CO}$ and $\mathrm{O}_{2}$ configuration is viewed as an IS, where $\mathrm{CO}$ and $\mathrm{O}_{2}$ are tilted and parallel to the Fe-GN4 surface, respectively. The FS consists of a physisorbed $\mathrm{CO}_{2}$ molecule and a chemisorbed $\mathrm{O}_{\text {ads }}$ at the Fe catalyst.

In the IS, the distance between $\mathrm{O}_{2}$ and $\mathrm{CO}$ is about $2.29 \AA$, and the $\mathrm{Fe}-\mathrm{CO}$ and $\mathrm{Fe}-\mathrm{O}_{2}$ distances are 1.77 and $1.90 \AA$, respectively. To react, the $\mathrm{O}_{2}$ molecule turns around with one of the oxygen atoms breaking away from the $\mathrm{Fe}$ atom and approaching the carbon atom of $\mathrm{CO}$ to generate a new $\mathrm{C}-\mathrm{O}$ bond, as shown in Fig. 5(a). Passing over the TS1, the OOCO complex (MS) is formed and the corresponding energy barrier $\left(E_{\text {bar1 } 1}\right)$ along the MEP is estimated to be $0.13 \mathrm{eV}$. In this reaction process, the bond length of $\mathrm{O}_{2}\left(d_{\mathrm{O} 1-\mathrm{O} 2}\right)$ is gradually elongated from 1.37 to $1.47 \AA$. The reaction continuously proceeds from the MS to FS through the TS2 without any energy barrier, where the $\mathrm{O} 1-\mathrm{O} 2$ and $\mathrm{Fe}-\mathrm{C}$ bonds are broken and $\mathrm{CO}_{2}$ molecule is generated, leaving an atomic $\mathrm{O} 1$ adsorbed at the $\mathrm{Fe}$ atom, which is expected to be active and can be used for the CO oxidation reaction. Once formed, the physisorbed $\mathrm{CO}_{2}$ will desorb easily from the reactive site. Then, we further check the oxidation process of a second $\mathrm{CO}$ reacting with the atomic $\mathrm{O} 1$ to produce
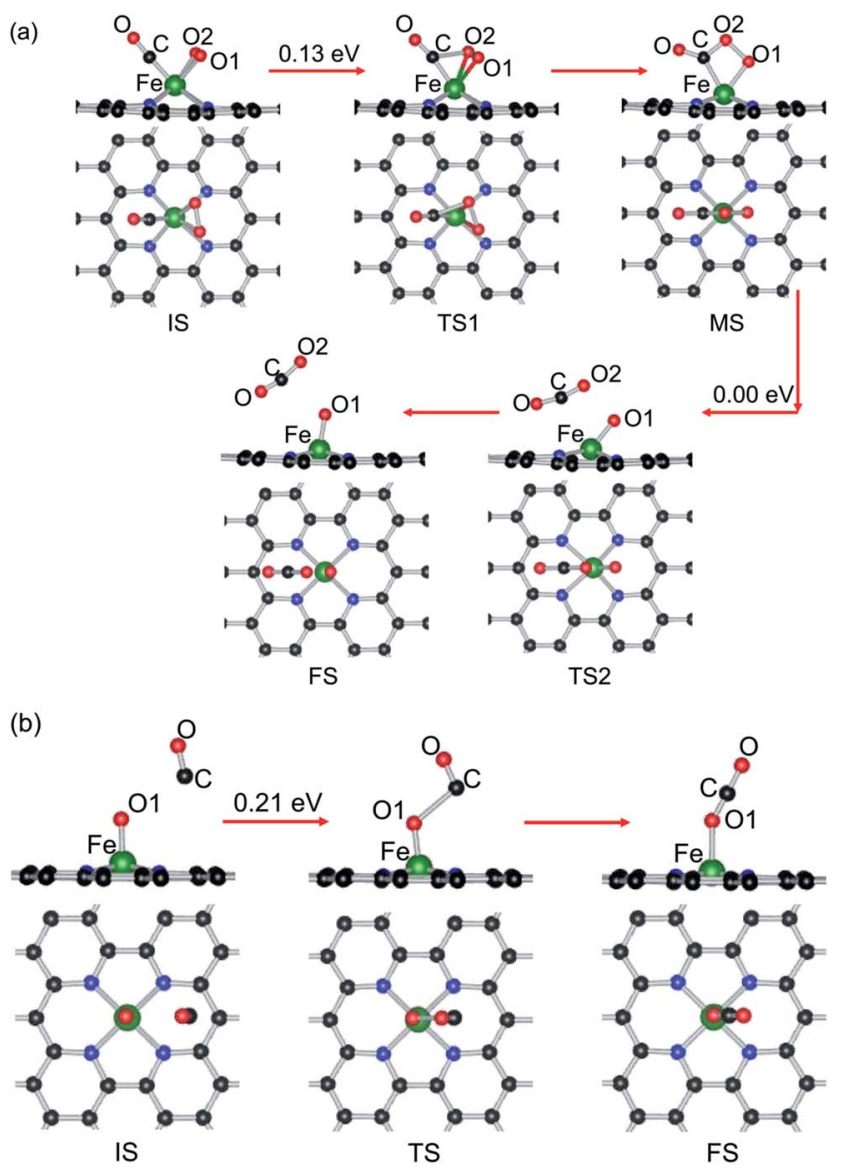

Fig. 5 The minimum energy profiles and the configurations of different states for $\mathrm{CO}$ oxidation on $\mathrm{Fe}-\mathrm{GN} 4$, (a) $\mathrm{CO}+\mathrm{O}_{2}$ by the $\mathrm{LH}$ mechanism and (b) $\mathrm{CO}+\mathrm{O}_{\text {ads }}$ by the ER mechanism. Black, blue, red and green balls represent the $\mathrm{C}, \mathrm{N}, \mathrm{O}$ and Fe atoms, respectively. 
Table 2 Structural parameters for the co-adsorption of $\mathrm{CO}$ and $\mathrm{O}_{2}$ for the IS, TS, MS and FS along the MEP for $\mathrm{CO}$ oxidation on $\mathrm{Fe}-\mathrm{GN}_{4}$, (a) the $\mathrm{LH}$ reaction $\left(\mathrm{CO}+\mathrm{O}_{2} \rightarrow \mathrm{OOCO} \rightarrow \mathrm{CO}_{2}+\mathrm{O}_{\text {ads }}\right.$ ), and (b) $\mathrm{ER}$ reaction $\left(\mathrm{CO}+\mathrm{O} \rightarrow \mathrm{CO}_{2}\right)$, as displayed in Fig. 5(a) and (b)

(a)

\begin{tabular}{llllll}
\hline Distance $(\AA)$ & IS & TS1 & MS & TS2 & FS \\
\hline$d_{\mathrm{C}-\mathrm{O}}$ & 1.16 & 1.17 & 1.21 & 1.17 & 1.08 \\
$d_{\mathrm{C}-\mathrm{Fe}}$ & 1.77 & 1.83 & 1.98 & 2.75 & 3.70 \\
$d_{\mathrm{C}-\mathrm{O} 2}$ & 2.29 & 1.82 & 1.33 & 1.18 & 1.20 \\
$d_{\mathrm{O} 1-\mathrm{Fe}}$ & 1.93 & 1.97 & 1.93 & 1.69 & 1.65 \\
$d_{\mathrm{O} 2-\mathrm{Fe}}$ & 1.90 & 1.99 & 2.56 & 2.96 & 4.17 \\
$d_{\mathrm{O} 1-\mathrm{O} 2}$ & 1.37 & 1.42 & 1.47 & 2.14 & 2.69 \\
\hline
\end{tabular}

(b)

\begin{tabular}{llll}
\hline Distance $(\AA)$ & IS & TS & FS \\
\hline$d_{\mathrm{O} 1-\mathrm{Fe}}$ & 1.65 & 1.66 & 1.93 \\
$d_{\mathrm{O}-\mathrm{C}}$ & 2.85 & 2.05 & 1.16 \\
$d_{\mathrm{C}-\mathrm{O}}$ & 1.15 & 1.16 & 1.18
\end{tabular}

$\mathrm{CO}_{2}$ through the ER reaction, the corresponding structural parameters and energy barrier of which are depicted in Table 2(b) and Fig. 5(b).

The configuration with a CO molecule more than $2.85 \AA$ away from the preadsorbed $\mathrm{O}_{\mathrm{ads}}\left(E_{\mathrm{ads}}, 4.56 \mathrm{eV}\right)$ on the $\mathrm{Fe}$ atom is chosen as the IS. The adsorption configuration of $\mathrm{CO}_{2}$ at $\mathrm{Fe}-$ GN4 is viewed as the FS. In the reaction process, the $\mathrm{C}$ atom of CO approaches the adsorbed $\mathrm{O} 1$ and the CO-O1 distance is 2.05 $\AA$, developing a new $\mathrm{C}-\mathrm{O} 1$ bond and attracting the adsorbed $\mathrm{O} 1$ at the Fe atom (TS). The calculated results show that the ER reaction has a relatively larger energy barrier $(0.21 \mathrm{eV})$ than that of the first step (TS1, $0.13 \mathrm{eV}$ ) through the $\mathrm{LH}$ reaction. It is noted that the $E_{\text {ads }}$ of $\mathrm{CO}_{2}$ on Fe-GN4 is only $0.12 \mathrm{eV}$ and it is easily desorbed from the reactive site at room temperature.

3.3.2. ER mechanism. On the other hand, as an important reference, the physisorbed $\mathrm{CO}$ molecule directly reacts with the preadsorbed $\mathrm{O}_{2}$ through the ER mechanism and the optimized structures of each state along the MEP are displayed in Fig. 6, as well as the corresponding structural parameters being shown in Table 3(a). As shown in Fig. 6(a), the configuration of CO suspended above the $\mathrm{O}_{2}$ preadsorbed on Fe-GN4 is taken as an IS. As the $\mathrm{CO}$ approaches the activated $\mathrm{O}_{2}$, the $\mathrm{C}-\mathrm{O}$ bond of $\mathrm{CO}$ and the $\mathrm{O}-\mathrm{O}$ bond of $\mathrm{O}_{2}$ are elongated simultaneously. Passing over TS1, the formation of a carbonate-like $\mathrm{CO}_{3}$ complex (MS) located on the Fe atom is produced by inserting $\mathrm{CO}$ completely into the $\mathrm{O}-\mathrm{O}$ bond and the corresponding energy barrier is $1.07 \mathrm{eV}$. Then, the reaction can proceed with the dissociation of $\mathrm{CO}_{3}$ into $\mathrm{CO}_{2}$ and leaving an atomic $\mathrm{O} 2$ (FS). The energy barrier for this process (TS2) is estimated to be $0.54 \mathrm{eV}$, which is quite similar to the case of $\mathrm{CO}$ oxidation on $\mathrm{Mo}^{-90}$ and Fe-embedded graphene ${ }^{59}$ and Pt-anchored graphene oxide. ${ }^{91}$ It is found that the formed $\mathrm{CO}_{3}$ has a larger energy barrier (TS1) than the formation of dissociative products ( $\mathrm{TS} 2, \mathrm{CO}_{2}$ and $\mathrm{O}_{\text {ads }}$ ), indicating that the breaking of the $\mathrm{O}-\mathrm{O}$ bond and formation of new $\mathrm{C}-\mathrm{O}$ bonds in the $\mathrm{CO}_{3}$ complex are rather difficult. (a)
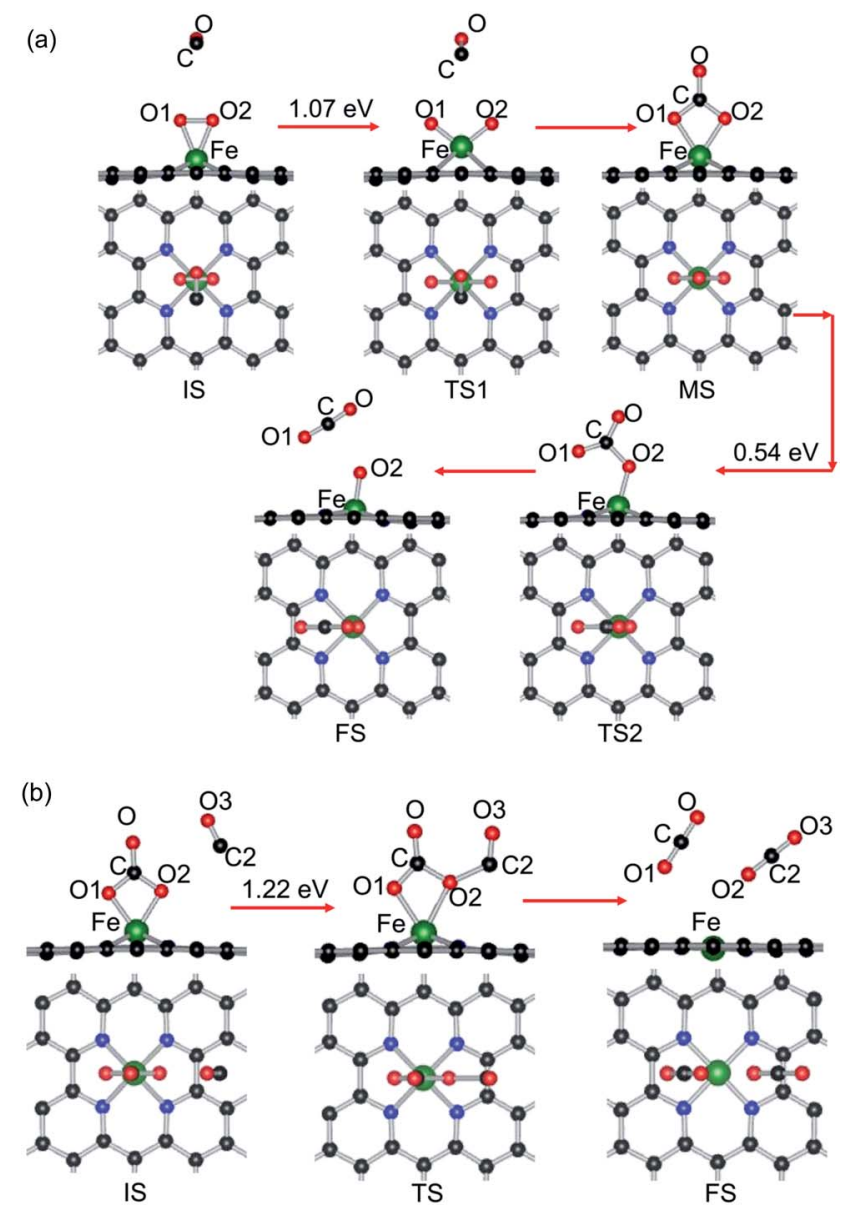

Fig. 6 The minimum energy profiles and the configurations of different states for $\mathrm{CO}$ oxidation on Fe-GN4, (a) $\mathrm{CO}+\mathrm{O}_{2}$ and (b) $\mathrm{CO}_{3}+\mathrm{CO}$ reactions by the ER mechanism. Black, blue, red and green balls represent the $\mathrm{C}, \mathrm{N}, \mathrm{O}$ and Fe atoms, respectively.

Furthermore, we consider another reaction pathway in which the formed $\mathrm{CO}_{3}$ reacts with a second $\mathrm{CO}$ molecule (IS) to generate two $\mathrm{CO}_{2}$ molecules (FS) through the TS, as shown in Fig. 6(b); the corresponding structural parameters are shown in Table $3(\mathrm{~b})$. In the reaction process $\left(\mathrm{CO}_{3}+\mathrm{CO} \rightarrow 2 \mathrm{CO}_{2}\right)$, the calculated energy barrier $(1.22 \mathrm{eV})$ is larger than the formation of the $\mathrm{CO}_{3}$ complex $(1.07 \mathrm{eV})$, illustrating that the dissociation of the $\mathrm{CO}_{3}$ complex in the presence of a $\mathrm{CO}$ environment is also more difficult.

For the reactive gases, although the $E_{\text {ads }}$ of CO is slightly larger than that of $\mathrm{O}_{2}$, the small energy difference may reduce the repulsion between the reactants and promote the catalytic reaction for $\mathrm{CO}$ oxidation, which is in agreement with that on $\mathrm{Au}$-graphene. ${ }^{58}$ Compared with the catalytic processes through the ER mechanism, the first step through the LH mechanism has a much smaller energy barrier $\left(\mathrm{CO}+\mathrm{O}_{2}(\mathrm{~b}) \mathrm{OOCO}, 0.13 \mathrm{eV}\right)$, while the second $\mathrm{CO}$ oxidation step (OOCO $\rightarrow \mathrm{CO}_{2}+\mathrm{O}$ ) is without any energy barrier, illustrating that the energy barrier for CO oxidation mainly comes from the formation of the OOCO complex, so the coadsorption of $\mathrm{CO}$ and $\mathrm{O}_{2}$ as the starting state is energetically favorable and then the reaction proceeds with 
Table 3 Structural parameters for the $\mathrm{CO}$ oxidation on Fe-GN4. The ER reaction including (a) $\mathrm{CO}+\mathrm{O}_{2} \rightarrow \mathrm{CO}_{3} \rightarrow \mathrm{CO}_{2}+\mathrm{O}_{\text {ads }}$ and (b) $\mathrm{CO}+$ $\mathrm{CO}_{3} \rightarrow 2 \mathrm{CO}_{2}$, and the corresponding reaction pathways (IS, TS, MS and FS) are displayed in Fig. 6(a) and (b).

(a)

\begin{tabular}{llllll}
\hline Distance $(\AA)$ & IS & TS1 & MS & TS2 & FS \\
\hline$d_{\mathrm{C}-\mathrm{O} 1}$ & 3.57 & 3.34 & 1.34 & 1.25 & 1.18 \\
$d_{\mathrm{C}-\mathrm{O} 2}$ & 3.57 & 3.34 & 1.34 & 1.44 & 2.58 \\
$d_{\mathrm{C}-\mathrm{O}}$ & 1.14 & 1.14 & 1.22 & 1.24 & 1.17 \\
$d_{\mathrm{O} 1-\mathrm{Fe}}$ & 1.85 & 1.63 & 1.93 & 2.95 & 3.90 \\
$d_{\mathrm{O} 2-\mathrm{Fe}}$ & 1.85 & 1.63 & 1.93 & 1.80 & 1.65 \\
$d_{\mathrm{O} 1-\mathrm{O} 2}$ & 1.40 & 2.60 & 2.14 & 2.28 & 2.91 \\
\hline
\end{tabular}

(b)

\begin{tabular}{llll}
\hline Distance $(\AA)$ & IS & TS & FS \\
\hline$d_{\mathrm{C}-\mathrm{O} 2}$ & 1.34 & 1.44 & 2.97 \\
$d_{\mathrm{C} 2-\mathrm{O} 2}$ & 3.05 & 1.66 & 1.18 \\
$d_{\mathrm{O} 1-\mathrm{Fe}}$ & 1.93 & 2.05 & 3.80 \\
$d_{\mathrm{O} 2-\mathrm{Fe}}$ & 1.94 & 2.18 & 3.28 \\
$d_{\mathrm{O} 1-\mathrm{O} 2}$ & 2.15 & 2.14 & 3.35 \\
$d_{\mathrm{C}-\mathrm{C} 2}$ & 3.70 & 2.75 & 3.65 \\
& & &
\end{tabular}

the second CO oxidation by the ER reaction. In addition, if the ER reaction is taken as the starting reaction step, the formation of the $\mathrm{CO}_{3}$ complex needs to overcome a large energy barrier. In contrast to the commonly used noble metal catalysts, such as $\mathrm{Pt}^{1,2}$ and $\mathrm{Au}^{92}(>1.0 \mathrm{eV})$, the $\mathrm{CO}$ oxidation reactions through the LH mechanism have a lower energy barrier on the Fe-GN4 surface $(0.13 \mathrm{eV})$; meanwhile, the energy barrier is also lower than that of the similar reaction on Fe- $(0.58 \mathrm{eV}),{ }^{59} \mathrm{Cu}-(0.54$ eV $),{ }^{61}$ Pd- $(0.54 \mathrm{eV}),{ }^{63} \mathrm{Pt}-(0.59 \mathrm{eV}),{ }^{62} \mathrm{Co}-(0.42 \mathrm{eV}),{ }^{74} \mathrm{Al}-(0.32 \mathrm{eV}){ }^{64}$ and Au-embedded graphene $(0.31 \mathrm{eV})^{58}$ and Co-N3-graphene $(0.86 \mathrm{eV}),{ }^{73}$ as well as Pd- $(0.66 \mathrm{eV})^{93}$ and Co-embedded (0.55 $\mathrm{eV})^{94}$ hexagonal boron nitride nanosheets. Hence, the formation of the Fe-GN4 sheet exhibits a much higher catalytic activity for CO oxidation.

In light of the aforementioned discussion, it is concluded that the adsorption of gas molecules can effectively regulate the electronic structure and magnetic property of the Fe-GN4 system. Besides, the sequential reactions of CO oxidation on the Fe-GN4 surface include the LH and ER reactions. For the $\mathrm{LH}$ reaction, the formation of the OOCO complex $\left(\mathrm{CO}+\mathrm{O}_{2} \rightarrow\right.$ OOCO, $0.13 \mathrm{eV}$ ) has a small energy barrier. Then, the second $\mathrm{CO}$ oxidation $\left(\mathrm{CO}+\mathrm{O} \rightarrow \mathrm{CO}_{2}, 0.21 \mathrm{eV}\right.$ ) has a slightly larger energy barrier, which can be viewed as the rate limiting step in the catalytic reactions. It is worth noting that the two-step CO oxidation reactions on Fe-GN4 have low enough energy barriers, so the $\mathrm{CO}$ oxidation reactions on the Fe-GN4 surface are more likely to proceed rapidly in practical reactions. Therefore, the calculated results show that the high quality FeGN4 sheet could be experimentally achieved, ${ }^{71,72}$ and the small energy barriers for the $\mathrm{CO}$ oxidation reaction indicate that the Fe-GN4 configuration has low cost and high activity.

\section{Conclusions}

We carried out a comprehensive study on the structural stability and $\mathrm{CO}$ oxidation reactions on a single-atom $\mathrm{Fe}$ incorporated GN4 sheet (Fe-GN4) by using the first-principles method. Firstly, it is found that the single-atom Fe can be stably embedded into the center of four $\mathrm{N}$ atoms and the small energy difference between reactant gases can facilitate the catalytic reaction towards CO oxidation. Secondly, the Fe dopant in the GN4 sheet introduces electronic doping and can effectively regulate the electronic structure and magnetic property of the graphene system. In the catalytic reactions, the LH mechanism as a starting state is more preferable than the ER mechanism, since the formation of the intermediate product (OOCO) has a smaller energy barrier $(0.13 \mathrm{eV})$. In comparison, the larger reaction barriers of $\mathrm{CO}_{3}$ formation and decomposition (1.02, 0.54 and $1.22 \mathrm{eV}$ ) reactions indicate that the $\mathrm{CO}$ oxidation through the ER mechanism is not preferable. As a result, the complete CO oxidation reactions on the Fe-GN4 surface include a two-step process: the $\mathrm{LH}$ as a starting step $\left(\mathrm{CO}+\mathrm{O}_{2} \rightarrow\right.$ OOCO $\left.\rightarrow \mathrm{CO}_{2}+\mathrm{O}_{\mathrm{ads}}, 0.13 \mathrm{eV}\right)$ followed by the ER reaction $\left(\mathrm{CO}+\mathrm{O}_{\mathrm{ads}}\right.$ $\left.\rightarrow \mathrm{CO}_{2}, 0.21 \mathrm{eV}\right)$. This result demonstrates the high catalytic properties of the Fe-GN4 sheet for $\mathrm{CO}$ oxidation, which provides a new opportunity for their applications in heterogeneous catalysis.

\section{Acknowledgements}

This work was supported by the National Natural Science Foundation of China (Grant No. U1404109 and 11504334), the Application Foundation and Advanced Technology Research Program of Henan Province (Grant No. 152300410167), the Natural Science Foundation of Henan Province (Grant No. 162300410325), Science Funds for Young Scholar of Henan Normal University (No. 5101029279082) and the Doctoral Research Fund of Henan Normal University (No. 5101029170256).

\section{References}

1 A. Alavi, P. Hu, T. Deutsch, P. L. Silvestrelli and J. Hutter, Phys. Rev. Lett., 1998, 80, 3650-3653.

2 M. Ackermann, T. Pedersen, B. Hendriksen, O. Robach, S. Bobaru, I. Popa, C. Quiros, H. Kim, B. Hammer, S. Ferrer and J. W. M. Frenken, Phys. Rev. Lett., 2005, 95, 255505.

3 C. Zhang and P. Hu, J. Am. Chem. Soc., 2001, 123, 1166-1172. 4 A. A. Herzing, C. J. Kiely, A. F. Carley, P. Landon and G. J. Hutchings, Science, 2008, 321, 1331-1335.

5 S. H. Oh and G. B. Hoflund, J. Catal., 2007, 245, 35-44.

6 X. Xie, Y. Li, Z. Q. Liu, M. Haruta and W. Shen, Nature, 2009, 458, 746-749.

7 Z. P. Liu, X. Q. Gong, J. Kohanoff, C. Sanchez and P. Hu, Phys. Rev. Lett., 2003, 91, 266102.

8 X. Q. Gong, Z. P. Liu, R. Raval and P. Hu, J. Am. Chem. Soc., 2004, 126, 8-9.

9 L. Molina and B. Hammer, Phys. Rev. Lett., 2003, 90, 206102. 
10 I. Nakai, H. Kondoh, K. Amemiya, M. Nagasaka, A. Nambu, T. Shimada and T. Ohta, J. Chem. Phys., 2004, 121, 5035.

11 M. Nagasaka, H. Kondoh, I. Nakai and T. Ohta, J. Chem. Phys., 2007, 126, 044704.

12 M. Chen, Y. Cai, Z. Yan, K. Gath, S. Axnanda and D. W. Goodman, Surf. Sci., 2007, 601, 5326-5331.

13 X. Liu, A. Wang, X. Wang, C. Y. Mou and T. Zhang, Chem. Commun., 2008, 27, 3187-3189.

14 S. N. Rashkeev, A. R. Lupini, S. H. Overbury, S. J. Pennycook and S. T. Pantelides, Phys. Rev. B: Condens. Matter Mater. Phys., 2007, 76, 035438.

15 C. Chang, C. Cheng and C. Wei, J. Chem. Phys., 2008, 128, 124710.

16 S. Dobrin, Phys. Chem. Chem. Phys., 2012, 14, $12122-12129$.

17 B. H. Morrow, D. E. Resasco, A. Striolo and M. B. Nardelli, J. Phys. Chem. C, 2011, 115, 5637-5647.

18 W. Liu, Y. Zhao, R. Zhang, Y. Li, E. J. Lavernia and Q. Jiang, ChemPhysChem, 2009, 10, 3295-3302.

19 C. Liu, Y. Tan, S. Lin, H. Li, X. Wu, L. Li, Y. Pei and X. C. Zeng, J. Am. Chem. Soc., 2013, 135, 2583-2595.

20 X.-F. Yang, A. Wang, B. Qiao, J. Li, J. Liu and T. Zhang, Acc. Chem. Res., 2013, 46, 1740-1748.

21 B. Qiao, A. Wang, X. Yang, L. F. Allard, Z. Jiang, Y. Cui, J. Liu, J. Li and T. Zhang, Nat. Chem., 2011, 3, 634-641.

22 F. Li, Y. Li, X. C. Zeng and Z. Chen, ACS Catal., 2015, 5, 544552.

23 D. Ma, Q. Wang, T. Li, Z. Tang, G. Yang, C. He and Z. Lu, J. Mater. Chem. C, 2015, 3, 9964-9972.

24 V. Shapovalov and H. Metiu, J. Catal., 2007, 245, 205-214.

25 W. C. Ding, X. K. Gu, H. Y. Su and W. X. Li, J. Phys. Chem. C, 2014, 118, 12216-12223.

26 J. Gao, C. Jia, L. Zhang, H. Wang, Y. Yang, S.-F. Hung, Y.-Y. Hsu and B. Liu, J. Catal., 2016, 341, 82-90.

27 D. Ma, Y. Tang, G. Yang, J. Zeng, C. He and Z. Lu, Appl. Surf. Sci., 2015, 328, 71-77.

28 C. Lee, X. Wei, J. W. Kysar and J. Hone, Science, 2008, 321, 385-388.

29 K. Novoselov, A. Geim, S. Morozov, D. Jiang, M. Katsnelson, I. Grigorieva, S. Dubonos and A. Firsov, Nature, 2005, 438, 197-200.

30 A. A. Balandin, S. Ghosh, W. Bao, I. Calizo, D. Teweldebrhan, F. Miao and C. N. Lau, Nano Lett., 2008, 8, 902-907.

31 A. Geim and K. Novoselov, Nat. Mater., 2007, 6, 183-191.

32 E. Yoo, T. Okada, T. Akita, M. Kohyama, I. Honma and J. Nakamura, J. Power Sources, 2011, 196, 110-115.

33 S. Sharma, A. Ganguly, P. Papakonstantinou, X. Miao, M. Li, J. Hutchison, M. Delichatsios and S. Ukleja, J. Phys. Chem. C, 2010, 423-427.

34 Y. Tang, Z. Yang and X. Dai, J. Nanopart. Res., 2012, 14, 844. 35 Y. Tang, Z. Lu, W. Chen, W. Li and X. Dai, Phys. Chem. Chem. Phys., 2015, 17, 11598-11608.

36 E. Yoo, T. Okata, T. Akita, M. Kohyama, J. Nakamura and I. Honma, Nano Lett., 2009, 9, 2255-2259.

37 R. Siburian and J. Nakamura, J. Phys. Chem. C, 2012, 116, 22947-22953.

38 G. Chen, S. J. Li, Y. Su, V. Wang, H. Mizuseki and Y. Kawazoe, J. Phys. Chem. C, 2011, 115, 20168-20174.
39 B. Seger and P. Kamat, J. Phys. Chem. C, 2009, 113, 79907995.

40 N. Cuong, A. Sugiyama, A. Fujiwara, T. Mitani and D. Chi, Phys. Rev. B: Condens. Matter Mater. Phys., 2009, 79, 235417. 41 Q. Tang, Z. Zhou and Z. Chen, Nanoscale, 2013, 5, 4541-4583. 42 A. Kasry, M. A. Kuroda, G. J. Martyna, G. S. Tulevski and A. A. Bol, ACS Nano, 2010, 4, 3839-3844.

43 M. N. Groves, C. Malardier-Jugroot and M. Jugroot, J. Phys. Chem. C, 2012, 116, 10548-10556.

44 T. W. Chen, J. Y. Xu, Z. H. Sheng, K. Wang, F. B. Wang, T. M. Liang and X. H. Xia, Electrochem. Commun., 2012, 16, 30-33.

45 A. Ambrosi, S. Y. Chee, B. Khezri, R. D. Webster, Z. Sofer and M. Pumera, Angew. Chem., Int. Ed., 2012, 51, 500-503.

46 J. A. Rodriguez-Manzo and F. Banhart, Nano Lett., 2009, 9, 2285-2289.

47 Y. J. Gan, L. T. Sun and F. Banhart, Small, 2008, 4, 587-591. 48 H. Wang, Q. Wang, Y. Cheng, K. Li, Y. Yao, Q. Zhang, C. Dong, P. Wang, U. Schwingenschlögl, W. Yang and X. X. Zhang, Nano Lett., 2012, 12, 141-144.

49 M. N. Groves, C. Malardier-Jugroot and M. Jugroot, J. Phys. Chem. C, 2012, 116, 10548-10556.

50 F. Li, J. Zhao and Z. Chen, J. Phys. Chem. C, 2012, 116, 25072514.

51 A. Krasheninnikov, P. Lehtinen, A. Foster, P. Pyykkö and R. Nieminen, Phys. Rev. Lett., 2009, 102, 126807.

52 O. Cretu, A. V. Krasheninnikov, J. A. Rodríguez-Manzo, L. Sun, R. M. Nieminen and F. Banhart, Phys. Rev. Lett., 2010, 105, 196102.

53 J. Rodriguez-Manzo, O. Cretu and F. Banhart, ACS Nano, 2010, 4, 3422-3428.

54 M. N. Groves, A. S. W. Chan, C. Malardier-Jugroot and M. Jugroot, Chem. Phys. Lett., 2009, 481, 214-219.

55 H. M. Jeong, J. W. Lee, W. H. Shin, Y. J. Choi, H. J. Shin, J. K. Kang and J. W. Choi, Nano Lett., 2011, 11, 2472-2477.

56 X. Zhang, Z. Lu, G. Xu, T. Wang, D. Ma, Z. Yang and L. Yang, Phys. Chem. Chem. Phys., 2015, 17, 20006-20013.

57 Y. Tang, Z. Yang, X. Dai, D. Ma and Z. Fu, J. Phys. Chem. C, 2013, 117, 5258-5268.

58 Y. Lu, M. Zhou, C. Zhang and Y. Feng, J. Phys. Chem. C, 2009, 113, 20156-20160.

59 Y. Li, Z. Zhou, G. Yu, W. Chen and Z. Chen, J. Phys. Chem. C, 2010, 114, 6250-6254.

60 Y. Tang, J. Zhou, Z. Shen, W. Chen, C. Li and X. Dai, RSC $A d v .$, 2016, 6, 93985-93996.

61 E. H. Song, Z. Wen and Q. Jiang, J. Phys. Chem. C, 2011, 115, 3678-3683.

62 Y. Tang, Z. Yang and X. Dai, Phys. Chem. Chem. Phys., 2012, 14, 16566-16572.

63 T.-T. Jia, C.-H. Lu, Y.-F. Zhang and W.-K. Chen, J. Nanopart. Res., 2014, 16, 1-11.

64 Q. G. Jiang, Z. M. Ao, S. Li and Z. Wen, $R S C A d v .$, 2014, 4, 20290-20296.

65 W. Orellana, J. Phys. Chem. C, 2013, 117, 9812-9818.

66 F. Calle-Vallejo, J. I. Martínez and J. Rossmeisl, Phys. Chem. Chem. Phys., 2011, 13, 15639-15643. 
67 S. Kattel, P. Atanassov and B. Kiefer, Phys. Chem. Chem. Phys., 2012, 15, 148-153.

68 S. Kattel, P. Atanassov and B. Kiefer, J. Phys. Chem. C, 2012, 116, 8161-8166.

69 C. W. B. Bezerra, Z. Lei, K. Lee, H. Liu, A. L. B. Marques, E. P. Marques, H. Wang and J. Zhang, Electrochim. Acta, 2008, 53, 4937-4951.

70 Z. Lu, G. Xu, C. He, T. Wang, L. Yang, Z. Yang and D. Ma, Carbon, 2015, 84, 500-508.

71 D. Deng, X. Chen, Y. Liang, X. Wu, Q. Liu, Y. Liu, H. Yang, H. Tian, Y. Hu and P. Du, Sci. Adv., 2015, 1, 1-9.

72 K. Liu, S. Kattel, V. Mao and G. Wang, J. Phys. Chem. C, 2016, 120, 1586-1596.

73 X. Zhang, Z. Lu and Z. Yang, J. Mol. Catal. A: Chem., 2016, 417, 28-35.

74 Y. Tang, D. Ma, W. Chen and X. Dai, Sens. Actuators, B, 2015, 211, 227-234.

75 Y. Tang, X. Dai, Z. Yang, Z. Liu, L. Pan, D. Ma and Z. Lu, Carbon, 2014, 71, 139-149.

76 G. Kresse and J. Furthmüller, Comput. Mater. Sci., 1996, 6, 15-50.

77 G. Kresse and J. Furthmüller, Phys. Rev. B: Condens. Matter Mater. Phys., 1996, 54, 11169-11186.

78 G. Kresse and D. Joubert, Phys. Rev. B: Condens. Matter Mater. Phys., 1999, 59, 1758-1775.

79 J. Perdew, K. Burke and M. Ernzerhof, Phys. Rev. Lett., 1996, 77, 3865-3868.

80 J. Carlsson and M. Scheffler, Phys. Rev. Lett., 2006, 96, 46806.
81 G. Henkelman, A. Arnaldsson and H. Jónsson, Comput. Mater. Sci., 2006, 36, 354-360.

82 G. Henkelman, B. Uberuaga and H. Jónsson, J. Chem. Phys., 2000, 113, 9901-9904.

83 G. Henkelman and H. Jónsson, J. Chem. Phys., 2000, 113, 9978-9985.

84 T. Zhu, J. Li and S. Yip, Phys. Rev. Lett., 2004, 93, 25503.

85 W. I. Choi, S. H. Jhi, K. Kim and Y. H. Kim, Phys. Rev. B: Condens. Matter Mater. Phys., 2010, 81, 085441.

86 Y. Feng, F. Li, Z. Hu, X. Luo, L. Zhang, X. F. Zhou, H. T. Wang, J. J. Xu and E. G. Wang, Phys. Rev. B: Condens. Matter Mater. Phys., 2012, 85, 4506.

87 L. M. Molina and B. Hammer, J. Catal., 2005, 233, 399-404. 88 W. An, Y. Pei and X. C. Zeng, Nano Lett., 2008, 8, 195-202.

89 M. Zhou, A. Zhang, Z. Dai, C. Zhang and Y. Feng, J. Chem. Phys., 2010, 132, 194704.

90 Y. Tang, L. Pan, W. Chen, C. Li, Z. Shen and X. Dai, Appl. Phys. A, 2015, 119, 475-485.

91 Y. Tang, X. Dai, Z. Yang, L. Pan, W. Chen, D. Ma and Z. Lu, Phys. Chem. Chem. Phys., 2014, 16, 7887-7895.

92 N. Lopez and J. K. Nørskov, J. Am. Chem. Soc., 2002, 124, 11262-11263.

93 Z. Lu, P. Lv, J. Xue, H. Wang, Y. Wang, Y. Huang, C. He, D. Ma and Z. Yang, RSC Adv., 2015, 5, 84381-84388.

94 Z. Lu, P. Lv, Y. Liang, D. Ma, Y. Zhang, W. Zhang, X. Yang and Z. Yang, Phys. Chem. Chem. Phys., 2016, 18, 2186521870. 